\title{
1. Language and global business expansion
}

We were exposed to five languages every day ... The official language of the authorities was Latvian, and 273 of the workforce and the local managing director spoke Russian only. English was so to speak our working tool ... With some of the older employees and with our German suppliers we communicated in German ... and amongst ourselves [the Danish expatriates], we obviously spoke Danish ... the constant need for translation is of course very time consuming. I was very fortunate, however, my secretary and interpreter, a young Latvian girl, was simply a linguistic talent. (Danish businessman's comment on his company's Latvian operation, in Jacobsen and Meyer, 1998, 11)

\section{INTRODUCTION}

To say that language permeates every facet of international business would meet with little argument, especially from those involved in global activities in any form. In the twenty-first century, as the globalization of business proceeds, it is exposing companies to a wider and wider array of the world's different languages. Despite the rise of technologies that are ameliorating some of the demands of communicating across languages, communication in the global village is becoming a more complex activity. Much of business still relies on social exchange, on person-to-person interaction, which is difficult to sustain through automated translation or through the use of professional translators. It has been estimated that if two countries have a common language, trade between them will be 42 per cent greater than between two countries that do not (The Economist, 2012a).

Ready acceptance of the importance of language, however, is not the same as understanding its role: where and how it is important; and what is the range of its effects? As Maclean $(2006,1377)$ comments, 'Companies deal with language issues every day, they cope, the world continues to turn. How they do so, however, remains largely absent from the literature.' The emerging work that attempts to redress this neglect is showing how an organization can be rendered partially deaf, mute and blind because of 
language effects, ultimately creating the silent organization (Lauring and Tange, 2010).

In this book, we delve into what goes on inside the internationalizing firm to reveal how language effects permeate activities across all levels of operation. We also explore the impact of language within and beyond firms and other institutions that are engaged in or impact upon international business activity. Thus we go beyond the obvious cross-cultural communication context. Instead, the book deals with language matters, or issues, that play an important role in furthering, or impeding, global expansion. By so doing, we aim to demonstrate how language matters in international business.

It should be noted that, throughout the book chapters, we use the generic term 'internationalizing firm' (rather than multinational corporation $\mathrm{MNC}$ - or other such labels) to indicate that the language issue confronts all firms - small, medium and large. We also use the terms 'company' and 'firm' interchangeably, reflecting common use.

\section{WHAT IS MEANT BY LANGUAGE?}

Language is a term that would seem not to need a definition. As McCrum et al. $(1986,14)$ comment, 'There is almost no aspect of our lives that is not touched by language. We live in and by language.' However, in discussions about the role of language at conferences and seminars, a common question posed is 'What do you mean by the term language? Surely it means more than foreign languages?' As a response to such questioning, Figure 1.1 was developed to exemplify the various sides, or layers, of language used in the workplace:

1. Everyday spoken/written language. Normal social language, that is, everyday spoken and written language employed for interpersonal, inter-unit and external communication. ${ }^{1}$

2. Company jargon. So-called 'company speak', replete with acronyms, special terms and management process terminology specific to the company, which evolves over time. For example, a new employee from the Hungarian subsidiary of Eastman Kodak reportedly asked if there was an Eastman Kodak to English standard dictionary to help her deal with the specialized internal language she was encountering (Welch et al., 2005; see also Tietze et al., 2003).

3. Technicallprofessional language. As with company jargon, there is a coded language that is common within and between groups, and can be used to include or exclude others from a specific group - what 


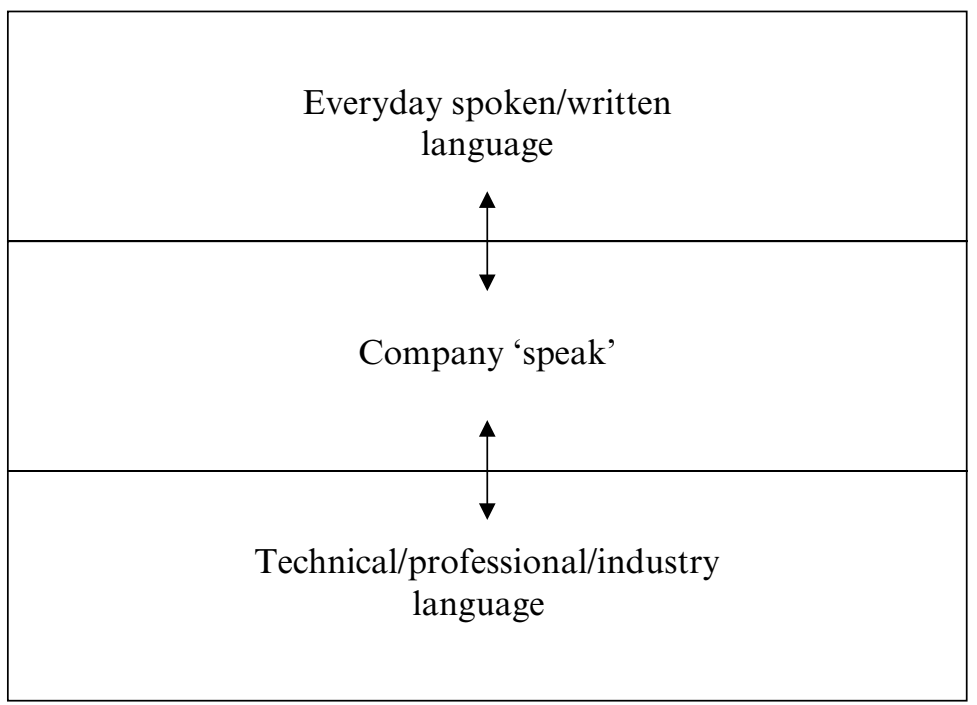

Source: Welch et al. $(2005,13)$.

Figure 1.1 Layers of language

Argote et al. (2003), term 'short-hand' and 'home-made' language (Nahapiet and Ghoshal, 1998; see also Hedlund, 1999). The intermingling of company terms with professional jargon can create barriers and compound miscommunication.

These layers of language are interconnected, as shown in Figure 1.1. In this book, we focus on everyday spoken and written language used within the workplace, though language is used more as an umbrella term. This reflects practice. For example, when an internationalizing firm transfers knowledge and information around its various global operations, there will be a mix of everyday language intermingled with company jargon and technical terminology.

Language, of course, is a key aspect of culture: it is inherent in a specific culture and also an embodiment of it: 'If language influences the way we behave and how we perceive things, it means that culture is also inherent in the language itself' (Claes, 1995, 99). But we deliberately take language out of what we have referred to elsewhere as the culture box. As Welch and Welch $(2008,341)$ argue, 'Language has an importance above and beyond the "embeddedness-in-culture" perspective.' This is not to underrate the importance of the cultural context. But we argue that there is a need to deal 
with language as a separate element in order to better understand its importance and role in international business. The organizational, social and national cultural contexts, however, remain a backdrop to our exploration.

\section{DOES LANGUAGE REALLY MATTER? THE RISE OF ENGLISH AS A LINGUA FRANCA}

A living language is like a man suffering incessantly from small haemorrhages, and what it needs above all else is constant transactions of new blood from other tongues. The day the gates go up, that day it begins to die. (Mencken, 1919, cited by McCrum et al., 1986, 47)

The English language is the sea which receives tributaries from every region under heaven. (McCrum et al., 1986, 11)

In presentations regarding language, we are often confronted with comments such as: 'Given the current IT context - the Internet and translation software - and the spread of English as the dominant business language, surely language is a disappearing problem?' Indeed, Tietze $(2004,176)$ notes that 'English is undisputedly the global lingua franca and serves as the communication tool of many intercultural encounters. This dominant position is also firmly established in the context of international trade and business.' It is telling that the Japanese e-commerce firm, Rakuten, has embraced English as its corporate language, to the extent of implementing an English-only policy in the Japanese headquarters. This was part of its efforts to become a truly global firm (The Economist, 2013c, 83).

There is ample evidence of the rise of English. The Economist has periodically commented on the role of English in international business. For example, in an article in the 22 December 2001 issue, it was estimated that 'over 85 per cent of all international organisations use English as one of their official languages' (p. 64). Earlier, in the 18 November, 2000 issue, The Economist reported 'Swiss multinationals, such as Swissair and UBS, conduct international business in English to save time and trouble' (p. 69). The Economist later commented on the results of a survey reinforcing the seeming dominance of English: in 1992, 44 per cent of UK executives surveyed indicated they were prepared to negotiate in a foreign language. Ten years later, only 28 per cent were prepared to do this (7 August 2004, 47). Perhaps an extreme example comes from a more recent article in The Economist (2013d, 12) about the interest in learning English in South Korea. Some parents have reportedly taken their children to an Englishspeaking country, or use the cheaper option of spending a summer in a specially created mock English village - called Gyeonggi English Village - where only English is spoken. 
An article in the International Herald Tribune on Mongolia reports that the Mongolian prime minister at the time outlined the importance of English in a bilingual future for the country. 'We see English not only as a way of communicating, but as a way of opening windows on the wider world ... With the English language, we can do outsourcing here, just like Bangalore' (Brooke, 2005, 2). It is not only the printed media that have been tracking the role of English. The $B B C$ News reported that 'a recent survey showed that seven per cent of French firms used English as their main language' (8 February 2007).

It is pertinent therefore to look at the development of English as a lingua franca in international business. According to Mann (2004), the term was originally coined in the Middle Ages by traders operating from Mediterranean ports as a way of coping with the differing languages: 'In order to carry on the business of trade, they spoke a common "patchwork" language consisting of bits of Italian mixed with Greek, French, Spanish, and Arabic words.' Mann notes that modern English retains some of this original mixed vocabulary. Seidlhofer $(2005,339)$ views English as having become a 'contact language'; that is, used as a means of communicating with others from different first-language backgrounds. We can find evidence of this within modern multinationals. For example, Sørensen's (2005) survey of 70 corporations operating in Denmark shows that the companies did not use English as an overruling language, but more generally as a 'transit language' between various parallel local languages. Once documents in English arrived at subsidiaries, they were translated into the respective local languages.

As the above example illustrates, while English is widely used in international business encounters, it has not rendered the world of international business monolingual. On the contrary, language diversity remains an issue. Indeed, The Economist has stressed that language remains a major barrier to the achievement of true integration of the European Union, commenting that 'language has replaced work visas as the main barrier to mobility' (2013b, 49). Louhiala-Salminen et al. (2005) launched a new area of study in the field of international business communication called Business English as a Lingua Franca (BELF), which underscores the multilingual reality of today's business contexts (Ehrenreich, 2010; Kankaanranta and Planken, 2010; Louhiala-Salminen and Kankaanranta, 2012). Some of this research has examined the role of English in the internal communication of globally operating firms (Louhiala-Salminen et al., 2005), while other studies have investigated language use in external relationships such as sales negotiations (Planken, 2005) or distributor meetings (Poncini, 2003). As Nickerson (2005) points out, 'the communication event is often considerably more complex than the label of English 
as lingua franca would suggest'. She explains that, in multinational settings, communication often takes place between non-native speakers of English who may also use one or more other languages alongside English (Marschan-Piekkari et al., 1999; see also Barner-Rasmussen, 2003). The impact that non-native speakers of English are having on the use of the English language is now an established stream of research in applied linguistics called English as a Lingua Franca (ELF), with its own dedicated journal.

For many, language salvation has come in the form of the rise of English as the global business language. Particularly for those from Englishspeaking backgrounds, this can be offered as a justification for regarding language as a peripheral management issue. But this is a sanguine view of the evolution of language in international discourse. Further, the rise of China as a global economic power means an inevitable rise in the importance and use of the Chinese language (or languages) as more firms enter China and Chinese firms internationalize. It has been estimated that 'there are currently 30 million people around the world learning Chinese as a second language' (Erard, 2006, 2). This process is being reinforced by a deliberate, funded government project to support the teaching of Chinese across a wide range of developed and developing countries.

The rise of Mandarin will increase the diverse language demands of international operations. For those drawing comfort from the role of English as the language of international business, there is a troubling future in store. A pertinent question to pose is: how would companies cope if Mandarin overtakes English as a world language? The rise of China as a twenty-first-century economic power will ensure that the English solution will be only partial. Of course, the rise of India will have some effect in cementing the place of English. Inevitably though, other languages, and even different versions of English, will have to be dealt with in the language mix that goes with international business. Readers may be aware of the efforts of nations such as France to protect their native languages from the vocabulary inroads made by English, particularly as a result of the global spread of information through films, music and the Internet. In contrast, one of the strengths of English is its dynamism; it is a living language that happily incorporates words from everywhere, continuing the tradition of the polyglot lingua franca of the Middle Ages. As Mann (2004) relates, 'before English infiltrated the world, many of the world's languages infiltrated English'. They continue to do so. According to McCrum et al. (1986), about 80 per cent of the English vocabulary is foreign born.

Another factor is the rise of social media, particularly the rapid adoption of Twitter. For some languages, such as Chinese, the number of characters needed to send a message via Twitter may be substantially reduced 
compared to English. On a global basis, tweets written in English have fallen from about 67 per cent of the global total in 2009 to 39 per cent in 2012 (The Economist, 2012b).

\section{LANGUAGE, COMMUNICATION AND INTERNATIONALIZATION}

Moving across language boundaries brings additional communication challenges for internationalizing firms. How these are handled is an important part of the ability to operate as a global entity. In a sense, communication is at the heart of any organization, even more so as language groups are added. Increasingly, managers face the decision as to which language will form the basis of the everyday spoken or written layer of Figure 1.1.

In considering the impact of language, it is useful to set it in the context of the basic communication model depicted in Figure 1.2. This demonstrates how a sender transmits a message to a receiver through a chosen medium: such as face to face, via email or text message, or over the telephone. The effectiveness of the communication depends on the ability of the sender to accurately encode a meaningful, complete message; the selection of the correct medium or channel of transfer; and the ability of the receiver to decode and understand the message as it was intended. Despite the communication process's seeming simplicity, communication scholars have long recognized that it is fraught with impediments referred

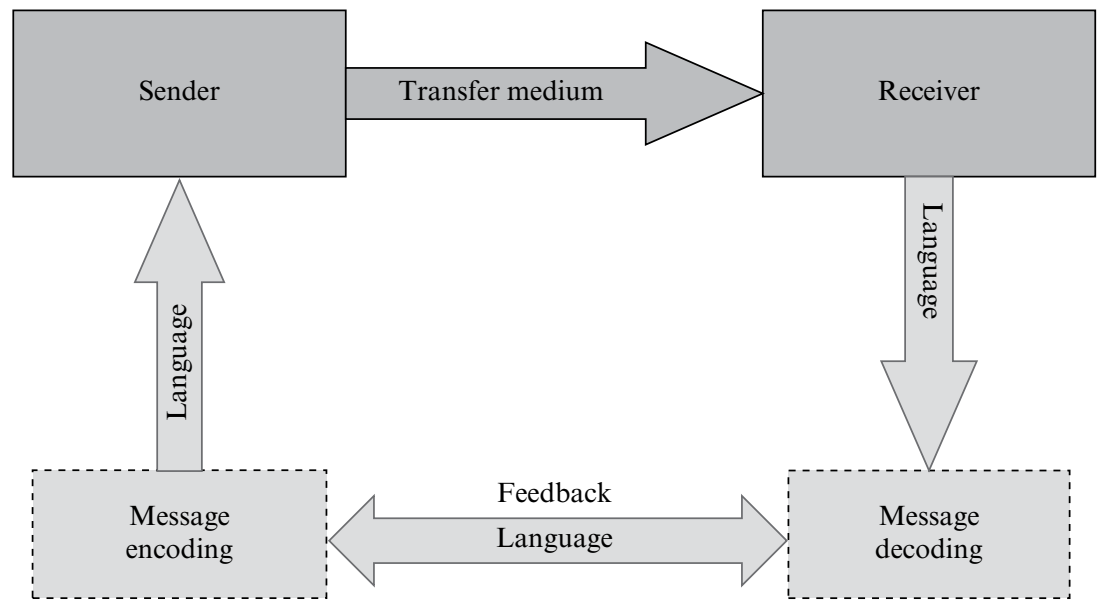

Figure 1.2 The basic communication model 
to as noise, distortion and leakage - and this is even the case where senders and receivers share a mother tongue. The communication process is thus subject to many influences that determine its success. Text messaging, for example, has developed its own short-hand language, including symbols to denote moods.

We have added language to the basic model in order to illustrate how language may interfere with the transfer and receipt of the communication. If the receiver is unable to decode the message because of the language used, translation may be necessary. As we examine in Chapter 2, translation involving intermediaries plays a key role in effective communication across language barriers. Picture language may also play a part in assisting effective communication. Feedback is an important element, which is why face-to-face communication remains the preferred medium, particularly when there are language differences between sender and receiver. Body language is often used as a feedback element to gauge whether the receiver has understood the message, though this is also subject to cross-cultural differences.

Being exposed to a different language highlights communication challenges. The following comment by the co-founder of Jetpak, an Australian asparagus-exporting company, is illustrative. In an interview, explaining his operations in its major market, Japan, he remarked:

You see, we're talking about a country [Japan] where you not only have a language problem but a written language problem. At least in Germany, sure, they speak German, but if you look at what's written, you can generally pick out some words, and understand what's going on . . . But in Japan, it's all bloody hieroglyphics.

One seemingly simple solution to the problems of operating in multiple language environments has been to impose a common corporate language (CCL) on the firm's internal interactions. Given its place as a business lingua franca, it is not surprising to find that English is often the first port of call when managers seek to address the language issue. This may be a deliberate decision, or English emerges into this role as internationalization proceeds.

While such an approach provides a range of benefits, it also often introduces unintended negative consequences. This was clearly brought out in our research on the Finnish multinational, KONE Corporation. The emergence and eventual adoption of English as the CCL meant that about two-thirds of its global workforce had to operate in a language other than their mother tongue (Marschan et al., 1997). The use of English as the corporate language can mask the subtle differences involved when parties are forced to operate in a second language. As Babcock and Du-Babcock 
$(2001,376)$ argue, 'it is not only the languages that international business communicators speak', but also the language fluency of such communicators that matters. In her study of international teams, Kassis Henderson $(2005,75)$ noted that, although one visible 'surface' language was used to facilitate communication, team members continued to use diverse interpretive mechanisms derived from their respective native tongues. She claims that when English is used as the working language, parties engaged in the exchange are 'under the false impression that they are sharing the same context and the same interpretation'.

Communication matters are not confined to the internal interactions between units of the internationalizing firm. A range of external stakeholders is involved: various national and international bodies; customers, suppliers, trade unions, media organizations and lobby groups. The method of international operation is also a factor. For instance, firms using cooperative forms such as strategic alliances, or growing through a process of acquisitions and mergers, face additional communication challenges. Interaction with external parties is language-dependent. The literature on social networks demonstrates the importance of individuals in the building and maintenance of internal and external networks. We deal with these various aspects in greater depth in later chapters.

\section{THE ROLE OF LANGUAGE IN THE STUDY OF INTERNATIONAL BUSINESS}

Despite the often acknowledged importance of language, it has been a surprisingly neglected subject of research in international business studies. In some respects, the impact of language in international business courses has been trivialized through a focus in many textbooks on inappropriate literal translation of notices, advertisements and product names in different language environments. In such instances, language is used to illustrate cross-cultural communication issues, using well-publicized 'blunders'. For example, the Sunday Times (22 November 1992) published a collection of literal translations under the heading: 'Written English: but what does it mean?' Examples included an Acapulco hotel notice regarding drinking water that translated as 'The manager has personally passed all the water served here'. A Bangkok dry cleaner asked potential customers to 'drop your trousers here for best results'; and a Japanese hotel notice to guests: 'You are invited to take advantage of the chambermaid'. In the classroom, everyone has a laugh about the obvious error that should have been anticipated and catered for. Discussion then moves on to 'more serious' concerns relating to, for example, negotiations, buyer behaviour in the 
foreign market, and cross-cultural management. Thus language is virtually dismissed as a back-translation omission, or treated at a relatively superficial level.

This has not always been the case. Language was emphasized in early studies of internationalization by companies, as a component of socalled psychic distance, a concept roughly equivalent to cultural distance. Early international business scholars used psychic distance to explain an observed bias of internationalizing companies towards foreign markets that were culturally similar (see, e.g., Johanson and Wiedersheim-Paul, 1975). Psychic distance was defined as factors preventing or disturbing the flow of information between the company's home country and the target foreign market. These factors included differences in culture, including language. The bundling of language into the 'culture' box appears to have ensured that language became 'the forgotten factor'. However, lately there have been some attempts to separate out language from the bundle of components that comprise psychic (or cultural) distance (see, e.g., Dow and Karunaratna, 2006; Dow and Larimo, 2009).

Similarly, studies of a broad range of international business issues (such as foreign direct investment, joint ventures and international knowledge transfer) either ignore language as a factor or assume that, by including culture, it has been accommodated. A case in point is the ballooning research and publications on international knowledge transfer. One would assume that knowledge transfer would inevitably involve language as a key component in the successful transfer of knowledge and technology to the various units and stakeholders of a multinational. However, a review of articles published in international business journals such as the special issues in Journal of International Business Studies (2004) and Management International Review (2005) demonstrates how language is virtually ignored (Welch and Welch, 2008). Consequently, one could draw a general conclusion that language in and of itself does not warrant separate treatment.

The aim of this book is to provide evidence to the contrary. The emerging research on which we draw demonstrates that language has a range of important effects: impacting on processes of communication, the effectiveness of knowledge transfer, and even acting as an internal restructuring mechanism. Language can deliver power to individuals and groups (see Chapter 3), and shape the creation of powerful networks within and beyond the firm (see Chapter 5). Language impinges on how the internationalizing firm approaches human resource management (HRM), including staff transfers, expatriate performance in foreign assignments and the career paths of employees (see Chapter 6). These wide-ranging consequences, both positive and negative, are examined in detail in this book. We follow the way in which language is part of the inner dynamics of 
organizations operating in the international arena. As well, we go beyond the organizational context and trace language-driven interactions across organizations into different cultures and marketplaces.

\section{LANGUAGE AND MANAGEMENT}

George Green, chief executive of Hearst Magazines International, is reported to have said that: He doesn't need to speak anything other than English as he travels the world to meet with publishing partners, with the exceptions of Japan and China, where translators are used. I won't let anyone who works for me have a conversation in a language other than English when I'm around. (Kranhold et al., 2004, B1)

As is the case with academics, managers within internationalizing firms could be accused of insufficient attention to the language proficiency levels of their employees and effects of language on their multi-country and multilingual operations. Few have conducted audits of the language competence levels of their employees (Reeves and Wright, 1996). This is somewhat understandable, as language effects are not always obvious. They are often opaque, not readily seen, and employees do not necessarily draw attention to their impact as this can be seen to reflect negatively on their performance. In part, this is because it is individual employees who are often faced with the need to deal with language problems on the spot, and readily devise solutions without the language issue necessarily becoming obvious elsewhere within the company. Upper management levels can be easily screened off from the realities of different language effects that might provoke more substantive responses. In Chapter 2, we provide examples of just how inventive employees can be in coming up with solutions to translation demands in the workplace, beyond the purview of others.

Language aspects are often viewed by management as a mechanical translation problem. When confronted with foreign languages, the response is often to regard these as constituting merely a technical problem that can be readily addressed through the use of interpreters and translators, particularly with the continuing development of automatic translation software and related devices. While there is a valid place for these language aids, it is difficult to engage in social interaction and develop close ties through such media (Hagen, 1999). In other words, translation is not the same as social communication and, as we will discuss later, does not ensure the creation of social capital or networks. There is also the question of security of commercial-in-confidence material, as well as the problem that technical information may be inaccurately translated (Crick, 1999; Maitland, 1999). 
Another way of seemingly removing the language problem is to view it as a selection issue: ensure that the company hires employees with the requisite foreign language skills and/or provide language training. As we will discuss in Chapter 6, it takes substantial time for a person to reach a level of operational fluency in another language, though the actual amount of time will vary depending on each individual's aptitude and motivation to learn. Firms face questions of whether to invest in the training of existing staff in the desired foreign language or whether to hire new staff with the appropriate language skills, assuming that such individuals are readily available. Either way, the company faces additional costs as well as the time constraint in achieving the necessary skills base. Hiring language skills may be possible if the internationalizing firm is establishing a 'greenfield' operation in a new market and is sourcing employees from the local area. In mergers and acquisitions, the acquirer inherits the set of language skills within the acquired organization (see Chapter 8).

\section{THE ROLE OF THE INDIVIDUAL EMPLOYEE}

While we stress the organizational context in our investigation of the role of language in international business, the issue is not only about organizations. Internationalizing firms are not in full control of individuals' utilization of their language skills for company purposes. As we explain later, language is part of individuals' human capital. Thus language as a resource for internationalizing firms is largely in the hands of their individual employees. Individuals make choices about whether, when and how they might employ any language skills they possess. They may choose whether or not to employ their foreign language skills for company benefit, or use them in a way that is contrary to company interests - in the same way that individuals make choices about whether and when to use knowledge and personal networks for company purposes (Marschan et al., 1996; Welch and Welch, 2008). Personal interests may dictate the type of action taken, while the ability to undertake any language-related tasks, such as translation, will be driven by the language skills and experience of an individual employee. Individual and organizational interests may coalesce, but this is not always the case, for example because of knowledge-sharing hostility (Michailova and Husted, 2003), the exercise of power (Marschan-Piekkari et al., 1999), lack of time (Marschan et al., 1997), or because the language task is outside and in addition to an individual's assigned job tasks. Thus, as Figure 1.3 illustrates, the reality for internationalizing firms is that foreign language use in and for a company is mediated or influenced by the individual. 


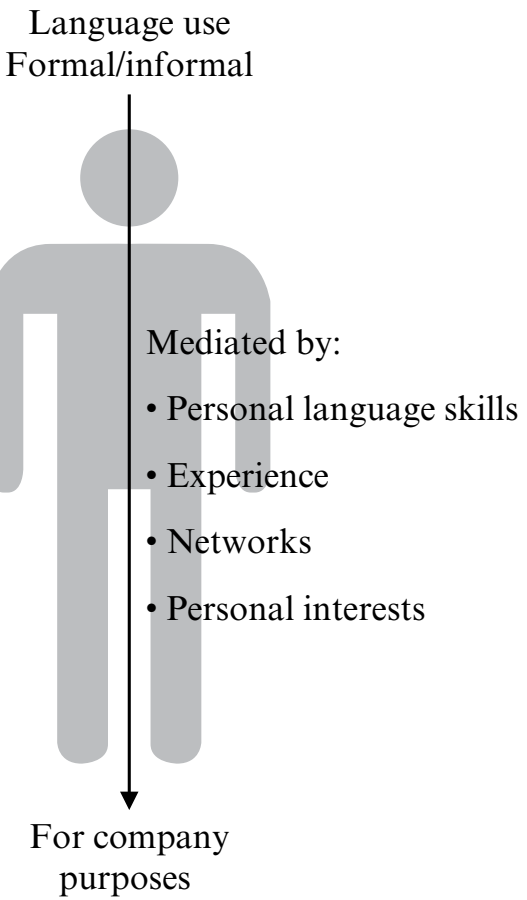

Figure 1.3 Personal factors influencing language use

Foreign language skills at the outset can create opportunities for an individual, at headquarters (HQ) or in different subsidiaries, which then lead to the creation of multi-country networks that the individual can call on for personal and/or company benefit over time. Alternatively, it may be through appointment to a position in a foreign language location that leads to an individual undertaking foreign language training, so as to perform the assigned job function more effectively, and the development of a related personal network. Internationalizing firms can shape the language development of individual employees through language policies and actions, for example in setting the language to be used in high-level international training programmes. In some cases, decisions with direct or indirect effects on language use are deliberate, but often they are not.

Individual and company drivers of language use overlap and interact in a dynamic process within shifting global contexts, as shown in Figure 1.4. Foreign language use is a complex by-product of individual and organizational interests as a result of this dynamic interaction. The aim of our 


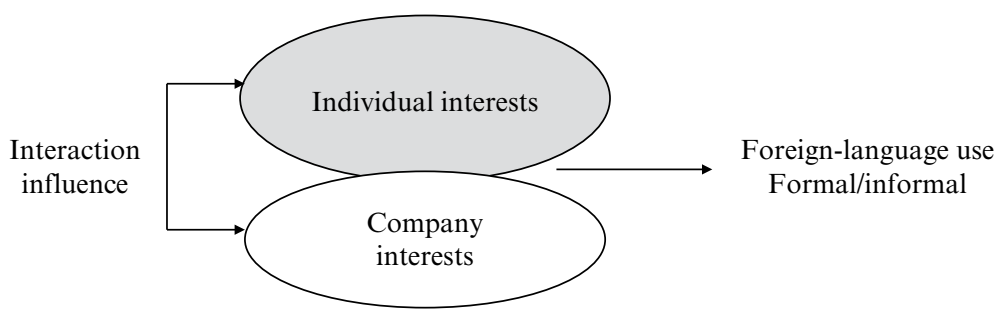

Figure 1.4 Interaction of individual and company interests

book, therefore, is to examine how these different interests play out as the firm internationalizes.

\section{LANGUAGE AND FOREIGN EXPANSION PATTERNS}

As firms continue to execute their international expansion strategies, at some point they cross language borders. One might argue that language is unimportant until that happens. However, it may be an implicit factor in decision-making in that certain markets are avoided because of the demands that different languages present. That is, language can be a silent influence even before a firm is confronted with the language barrier. It is well known from early studies into the impact of psychic distance that many firms are influenced by cultural factors in their selection of foreign markets. As noted above, language is part of psychic distance (Johanson and Wiedersheim-Paul, 1975). Of course, this is not surprising. International marketers feel more at home in foreign markets that have a common language. We now examine how language affects the internationalization process, and how individuals and firms respond to the challenges that it poses.

For a firm beginning international operations, going to a market where one's own language is used is one way of coping with the risks and uncertainties such a move entails. Staying within one's language comfort zone not only helps reduce psychic distance, but also has business advantages, particularly for firms in the early stages of internationalization. First, it is easier and cheaper to collect and process information pertaining to a foreign market that is using the same language as it removes the need for translation. Second, it is easier to build contacts and negotiate in one's mother tongue. Third, promotional activities, such as advertising, may be much cheaper to undertake. For example, promotional material from 
the home market sometimes requires little or no alteration for markets sharing a language. There are cases of firms being able to utilize advertising campaigns across markets that share a language, including television campaigns, although there are dangers in the assumption that language similarity equates with market similarity (O'Grady and Lane, 1996). Research in the UK found some exporters recruited foreign intermediaries as much on the basis of English fluency as on their selling ability (Crick, 1999).

It is not always, though, a conscious decision to select foreign markets on the basis of language or cultural compatibility. The exporting literature shows that frequently, in some studies overwhelmingly, the start into exporting is driven by foreign approaches (Bilkey and Tesar, 1977; Austrade, 2001). Often, individuals approach companies fortuitously, seeking to import their products or services or to act as agents in their own home market. Such approaches are more likely when the countries concerned have a similar culture and language. For instance, the Australian company, Ronstan, a leading global supplier of fittings for yachts and other marine hardware, had given no particular consideration to the possibility of exporting. However, in 1965 an order was received from Canada from a Canadian airline pilot who had become familiar with the products on visits to Australia and who saw a potential for them in the Canadian market. As Dow and Larimo (2009) point out, the size of a foreign market may prompt firms to hop the language barrier at an earlier stage as the prize of a large market beckons. However, if we take Australian firms' slow reaction to the potential that Japan offered, a large market per se may not be enough of a trigger for internationalizing firms to compensate for language and cultural barriers.

As Figure 1.5 indicates, the impact and timing of language effects on international expansion by companies in part depends on the starting point - that is, the home-country language base. By its very nature, global expansion ensures that the company eventually crosses the language barrier, though the point at which this occurs varies according to the home-language starting point and the growth strategies pursued by individual companies. What can be observed first is the impact of what we call the Empire and the Diaspora language paths.

\section{The Empire Language Path}

Colonial heritage brings together a unique combination of language, history, and economic and business ties. Empire brings language in its train: French in parts of Africa; English in countries such as India, Singapore, parts of Africa, and the Caribbean. Following the Empire 


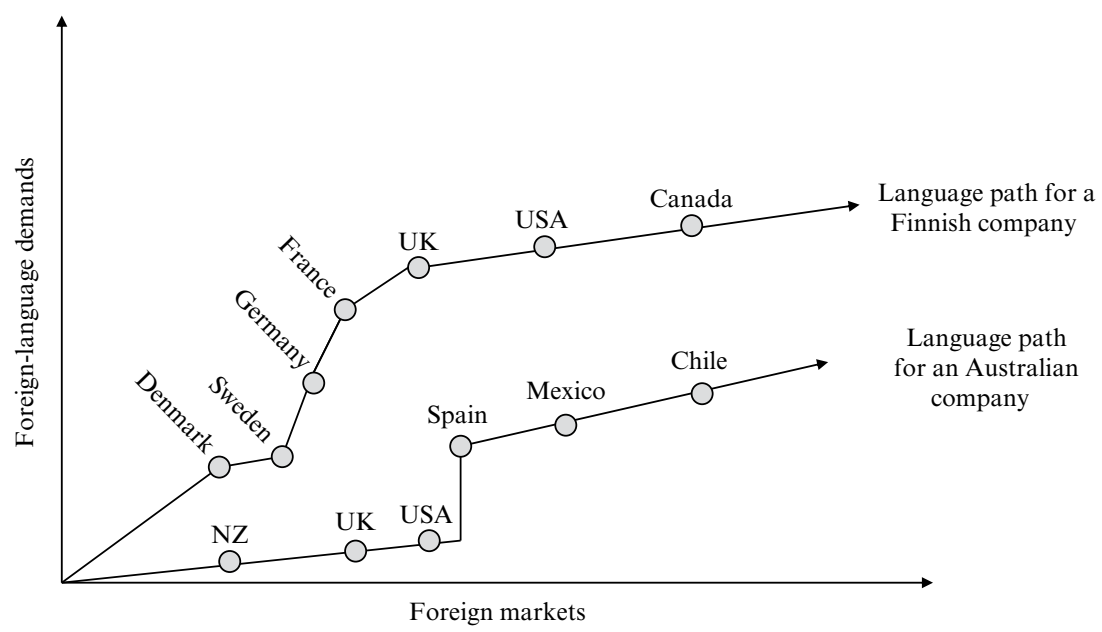

Figure 1.5 Hypothetical company patterns

route may be a mixture of conscious and unconscious factors operating to affect key decision-makers' perceptions that drive internationalization. Given the wider spread of English, companies from English-speaking countries can undertake expansion to a higher degree before encountering language barriers. To a certain extent, this pattern may even be extended to countries with high levels of English competence, such as the Netherlands, Denmark, Sweden and Norway.

Spanish is spoken in countries that once formed the 'Spanish Empire' and hence the heavy involvement of Spanish firms in Latin America. As White $(1997,13)$ states, 'Over the past few years, Spain has become the largest European investor in the region ... Spanish executives say this bias is explained by language and cultural ties, close knowledge of the countries involved, and a confidence in Latin America's future.' In a study of the determinants of the location decisions of Spanish multinationals over the period 1988 to 1997, Barrios and Benito-Ostolaza (2008, 14) separated language from its cultural link and found that 'Spanish FDI [foreign direct investment] abroad has been strongly influenced by language proximity'. This language path continues, but is also now operating in reverse. In US dollar value terms, mergers and acquisitions by Latin American firms in Spain exceed those in the opposite direction, with Latin American firms using Spain as a springboard to wider markets (The Economist, 2014).

Firms based in one Empire group can take advantage of other Empire languages, as the hypothetical path taken by the Australian company in 
Figure 1.5 illustrates. It first enters the English-speaking markets, taking advantage of the cultural, including language, similarities and historical ties. Its UK operation may bring Spain closer due to EU interrelations at the business level and the firm decides to enter the Spanish market. Based on the market knowledge gained regarding the Spanish way of doing business, and exposure to the Spanish language, the firm may then feel confident enough to follow the Spanish-language path and expand into Mexico, given its geographical closeness to the US operation, and other Latin American countries such as Chile.

However, for a Finnish firm, coming from a language base of Finnish and Swedish, a conscious decision to expand only where Finnish or Swedish is spoken would restrict it to Sweden and Estonia, a country whose language is close enough to Finnish for a surface-level understanding. Given the small Russian-speaking minority in Finland, expansion into Russia is viable. However, Swedish provides the basis to expand across the Nordic region through what is referred to as Scandinavian language - a mixture of the Scandinavian languages, coupled of course with cultural commonalities (Marschan-Piekkari et al., 1999). Early Nordic research indicated a preference for Finnish firms to move into neighbouring markets first before moving to continental European countries and further afield, as indicated in the hypothetical path depicted in Figure 1.5. The simple business reality is that Finnish firms cannot rely on the use of Finnish beyond their home market. To some extent, this has been alleviated by the rise of English as a lingua franca and the fact that English has moved to the point of being an unofficial second language within Finland. This is particularly evident among younger Finns, who have grown up with a substantial use of English, through education and reinforced by exposure to English-based media such as MTV, the Internet, and the like. In other words, foreign market choices immediately force language questions to the forefront.

\section{Diaspora Language Path}

There is only limited early evidence of how language is, or may be, affecting the international expansion of Chinese firms. Some insight may be gained from the behaviour of overseas Chinese-owned firms in parts of East Asia that tap into the so-called 'bamboo network' of the Chinese Diaspora. During the nineteenth and early twentieth centuries, most of the Chinese who migrated from China during this period were from the southern coastal provinces of Guangdong, Fujian and Hainan. A study of these networks highlighted how dialect was a critical part of the connections formed throughout East Asia: 
Even today, ethnic Chinese may differentiate among themselves according to dialect, sub-dialect, clan and family, all of which are linked to their place of ancestral origin in China ... In this manner, the ethnic Chinese created a cohesive web of interlocking organizations and relationships that provided a firm and stable framework within which traditional society could be recreated, maintained, and developed and whose individual members could prosper far from home. (Backman, 1995, 2)

The study stresses how 'understanding the importance of dialects and their distribution across East Asia is central to an understanding of how ethnic Chinese business networks operated in the past, and operate in the present'.

Personal networks are enabled by language, and as Backman's (1995) study shows, the Chinese rely heavily on networks to conduct business. An example cited in this work is the dominance of Teochiu speakers in many sectors of South-East Asia's food trade. Thus the language picture is somewhat complicated by the various dialects of Chinese (such as Mandarin, Cantonese, Hokkien and Teochiu) used by the Diaspora, and a Mandarin speaker dealing with a Hokkien speaker may have difficulties tapping into the network. In a situation experienced by two of the authors, overseas-born Chinese from three different South-East Asian countries living close to each other used English on social occasions as one person could not interact freely because he could only use Hokkien while the others could only converse in Cantonese.

Using the networks and language benefits through the Chinese Diaspora, Chinese firms may be able to extend the point at which the language barrier is confronted in a major sense. Eventually, though, as with firms using the Empire path, language differences have to be dealt with. The sheer size and range of exports to, and other operations in, the USA mean that internal English competence has to be developed. This can be very dramatic in some cases - such as Lenovo's acquisition of IBM's personal computer business (The Economist, 2013a). There have been examples of the hiring of US overseas-born Chinese to head up Chinese operations in the USA; and where members of the Chinese Diaspora have returned to China, established businesses and then commenced international expansion from China. As we will discuss later in Chapter 6, the buying in of language competence through selection decisions is a well-used response.

Of course, as the influence of China in the world economy and on global trade and investment increases, there will be a reverse impact: firms from other countries will be forced to develop Mandarin competence. As a Chinese student in an MBA course in Beijing, conducted by two of the authors, commented: 'English is difficult. It will be nice when Chinese companies become so global that you will be forced to use Chinese.' 
India is a different case. While Hindi and English are the official languages, there are 14 recognized regional languages, plus numerous local dialects. Given the official place of English as a unifying language within India, one could assume that Indian companies would be similar to those from other former British colonies and have the advantage of following the Empire path, with the added advantage of tapping into the global Indian Diaspora network.

While a Diaspora network can be useful for internationalizing firms, providing a powerful external resource to assist in penetrating foreign markets, it can be somewhat restrictive. Rapid penetration of a narrow segment in a foreign market can take the entrant firm only so far. At some point, it will still be necessary to move beyond the Diaspora network, crossing language and cultural barriers into the broader market context in order to grow. Elo (2013) provides the case of a Greek small and medium-sized enterprise that was able to use the Greek Diaspora to expand internationally into quite diverse markets, using only the Greek language. However, various difficulties arose due to the intensely personal nature of the networks established. This case highlights how reliance on language-based networks can be limiting, and can generate superficial internationalization.

\section{Large Countries, Different Language Paths}

Japanese firms face a similar language challenge to those from Finland, in that outside Japan there is limited scope to use Japanese. However, compared to Finland, the Japanese domestic market is large, and Japan holds a different geopolitical status. Such power bestows influence - not the least through buying power, which means that those seeking to sell into the Japanese market have to devise appropriate language solutions, such as the use of translators.

Many Japanese firms have traditionally used trading companies to handle their international operations, thus effectively outsourcing the language issue. These large trading companies still play a significant role in Japan's international [business] activities, accounting for more than half of Japan's total foreign trade. (Welch et al., 2001, 197)

The choice of the UK for many early Japanese greenfield investments was strongly influenced by the ability to use English: 'Since most of the companies had production facilities in the US, the presence of production engineers with international experience and English language ability was regarded as critical' (Hood and Truijens, 1993, 54). In a study of Hong Kong exporters, Ellis (2000, 461) found, somewhat surprisingly, that 'more than two-thirds of early entries into the EU were to non-English 


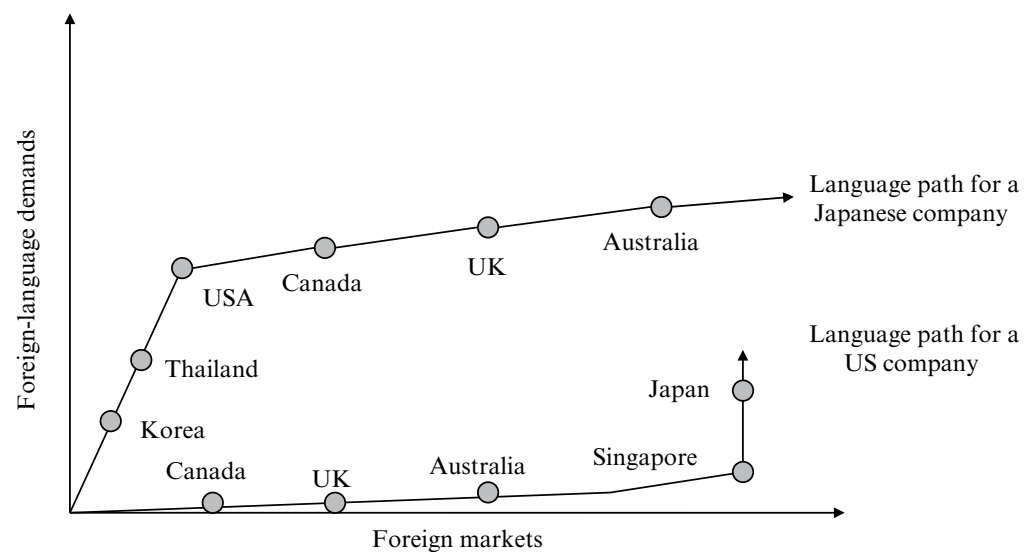

Figure 1.6 Divergent language paths of two large countries

speaking countries'. However, 'almost 90 per cent of these entries were not initiated by the [Hong Kong] manufacturer'. Because of the lack of requisite language ability, a party with the necessary language competence had to intervene - that is, the EU buyer or a third party (such as a broker).

As Figure 1.6 illustrates, many Japanese firms have moved into Englishspeaking countries, developed language and other cultural competences, and then been able to continue an expansion path based on Englishspeaking markets. Japanese firms have been able to move into countries such as the Netherlands and Finland, due to the higher level of English fluency found within such countries. Tapping into the English Empire language path can provide certain language economies of scale.

On the other hand, as Figure 1.6 illustrates, US firms can follow the English Empire path but movement into markets such as Japan will mean a very steep jump in language demands. On the surface, the Empire path can provide firms from English-speaking countries with a language advantage, but, as we will later demonstrate, this may mask communication issues that affect performance. O'Grady and Lane (1996) argued that familiarity can breed false confidence and carelessness, and termed this phenomenon the 'psychic distance paradox'. Following along an Empire path can produce false confidence, even hubris - what we would call the paradox of language distance.

Previous research provides supporting evidence. Fixman (1990, 33-4) indicates that, even when moving into non-English-speaking countries, there can be a perception that foreign languages are not important: 'Most individuals whom I interviewed perceived foreign languages to be of only secondary value for executives ... One executive explained 
that he really can "get by almost anywhere in the world without foreign language ability".' Tung's (1998) study found that respondents from the English-speaking countries of the USA, the UK, Canada and Australia deemed expatriate language skills as unimportant. In Figures 1.5 and 1.6, the mildly sloping line on the Empire language paths depicts subtle differences: versions of English and Spanish, for example, reflect the broader sociocultural, political and economic environments in which these languages are spoken. Thus, within language groups there may be still mild language barriers to cross. Further, Fixman (1990, 31) found that company size matters: 'Smaller companies, however, enter the global market place without the English-speaking networks to which their larger counterparts have access.' This constrained their ability to market products in foreign language domains.

In contrast, firms from countries such as Japan and Finland have to cope with foreign language demands from the earliest stages of international expansion. This means that they have to develop mechanisms, competence and procedures that assist in overcoming or at least managing language matters. It becomes a more basic feature of their approach to international operations. Nevertheless, all the hypothetical firms depicted in the above figures eventually have to cross the language barrier. To a greater or lesser extent, this unleashes a range of managerial actions such as language training, language-based staff appointments and the like, ultimately generating learning about the role of language that potentially can be leveraged in subsequent market expansion moves.

Foreign expansion paths are not exclusively language-determined. There is a complex interaction between foreign-market expansion and language paths. As with the role of Japanese trading companies for Japanese exporters, internationalizing firms are able to structure operation modes so as to minimize the need to operate in foreign languages, though this may not be the paramount driving factor in the decision of which mode to select. We take up these aspects in Chapter 8.

Obviously, firms do not have languages; people do. Individuals and their background experience, including foreign language competence, play a critical role in determining how language feeds into foreign expansion processes. This emerged in a study of 144 newly internationalizing Italian firms (Zucchella et al., 2007, 277). The authors looked at factors that drove the expansion and confirmed the importance of entrepreneurial characteristics, including educational background. Of these, knowledge of foreign languages was the most statistically significant variable affecting early internationalization. Discussing this result, they conclude: 'This [knowledge of foreign languages] is a pre-requisite for people who want to develop business contacts abroad and it helps in the formation of an international mindset.' 
An individual may have the capacity to change the language path of an internationalizing company. There are examples in the literature of firms making decisions on which foreign markets to enter on the basis of the language background of key personnel. In one case, the company advanced the timing of its foreign direct investment in Europe because a member of staff was returning to his country of origin. Thus migrants may become language bridge-builders and promote language-driven internationalization. 'The migrant effect can operate at two levels: as key decision-maker, a migrant may select markets on the basis of former country familiarity; or the migrant as employee may trigger or confirm the attractiveness of a selected market, and language may be a major factor' (Welch et al., 2001, 194). These choices can be contrary to national psychic distance patterns.

In this introductory chapter, we have raised a wide range of issues connected with the impact of language on internationalizing firms. The remainder of this book explores how internationalizing firms respond to the multilingual reality of global expansion. We also include individual employees' responses and how these impact on what organizations are able to accomplish on the language front.

\section{NOTE}

1. Such as English or French, in contrast to discourses, which can be understood as 'framing devices, systems of shared meaning' used in speaking or writing about a particular subject matter (Tietze et al., 2003, 78).

\section{REFERENCES}

Argote, L., B. McEvily and R. Reagans (2003), 'Managing knowledge in organizations: an integrative framework and review of emerging themes', Management Science, 49 (4), 571-82.

Austrade (2001), Knowing \& Growing the Exporter Community, Sydney: Austrade.

Babcock, R.D. and B. Du-Babcock (2001), 'Language-based communication zones in international business communication', Journal of Business Communication, 38 (4), 372-412.

Backman, M. (1995), Overseas Chinese Business Networks in Asia, East Asia Analytical Unit (EAAU), Canberra: Department of Foreign Affairs and Trade, Australian Government.

Barner-Rasmussen, W. (2003), Knowledge Sharing in Multinational Corporations: A Social Capital Perspective, Doctoral Thesis No. 113, Helsinki: Swedish School of Economics and Business Administration.

Barrios, S. and J.M. Benito-Ostolaza (2008), 'The location decisions of multinationals and the cultural link: evidence from Spanish direct investment abroad', Working Paper D.T.2008/04, Universidad Pública de Navarra. 
BBC News (2007), 'French fury over English language', 8 February, international online version, accessed 6 March 2007.

Bilkey, W.J. and G. Tesar (1977), 'The export behavior of smaller-sized Wisconsin firms', Journal of International Business Studies, 8 (1), 93-8.

Brooke, J. (2005), 'Mongolians learn to say "progress" in English', International Herald Tribune, 14 February, 2.

Claes, M.-T. (1995), 'A case study of language overlap and cross-cultural communication problems', Interface Journal of Applied Linguistics, 10 (1), 99-111.

Crick, D. (1999), 'An investigation into SME's use of languages in their export operations', International Journal of Entrepreneurial Behaviour and Research, 5 (1), 19-31.

Dow, D. and A. Karunaratna (2006), 'Developing a multidimensional instrument to measure psychic distance stimuli', Journal of International Business Studies 37, 578-602.

Dow, D. and J. Larimo (2009), 'Challenging the conceptualization and measurement of distance and international experience in entry mode choice research', Journal of International Marketing, 17 (2), 74-98.

The Economist (2000), 'Fifth tongue, fifth column?', 18 November, 69.

The Economist (2001), 'A world empire by other means', 22 December, 63-5.

The Economist (2004), 'Oh là là', 7 August, 47.

The Economist (2012a), 'The power of tribes', 28 January, 60.

The Economist (2012b), 'Twtr', 31 March, 66.

The Economist (2013a), 'From guard shack to global giant', 12 January, 52-3.

The Economist (2013b), 'English to the fore', 13 April, 83.

The Economist (2013c), 'Parallel worlds: a special report on the Koreas', 26 October, 12.

The Economist (2014), 'Shoe on the other foot', 25 January, 35-6.

Ehrenreich, S. (2010), 'English as business lingua franca in a German multinational corporation: meeting the challenge', Journal of Business Communication, 47 (4), 408-31.

Ellis, P. (2000), 'Social ties and foreign market entry', Journal of International Business Studies, 31 (3), 443-69.

Elo, M. (2013), 'How Diaspora networks make impossible possible? The internationalization story of one non-English speaking Greek SME', Paper presented at the 39th EIBA conference, University of Bremen, 12-14 December.

Erard, M. (2006), 'The Mandarin offensive', Wired Magazine, retrieved 8 May 2006 from http://www.wired.com/wired/archive/14.04/mandarin_pr.html.

Fixman, C.S. (1990), 'The foreign language needs of U.S.-based corporations', Annals of the American Academy of Political and Social Science, 511, 25-46.

Hagen, S. (1999), Business Communication Across Borders: A Study of Language Use and Practice in European Companies, London: Languages National Training Organization in association with Centre for Information on Language Training and Research.

Hedlund, G. (1999), 'The intensity and extensity of knowledge and the multinational corporation as a nearly recomposable system (NRS)', Management International Review, 39 (Special Issue 1), 5-44.

Hood, N. and T. Truijens (1993), 'European locational decisions of Japanese manufacturers: survey evidence on the case of the UK', International Business Review, 2 (1), 39-64. 
Jacobsen, M.K. and K.E. Meyer (1998), 'Opportunities in Russia: internationalization of Danish and Austrian businesses', Working Paper No. 17, Center for East European Studies, Copenhagen Business School, Copenhagen, Denmark.

Johanson, J. and F. Wiedersheim-Paul (1975), 'The internationalization of the firm: four Swedish cases', Journal of Management Studies, 12 (3), 305-22.

Kankaanranta, A. and B. Planken (2010), 'BELF competence as business knowledge of internationally operating business professionals', Journal of Business Communication, 47 (4), 380-407.

Kassis Henderson, J.K. (2005), 'Language diversity in international management teams', International Studies of Management and Organization, 35 (1), 66-82.

Kranhold, K., D. Bilefsky, M. Karnitschnig and G. Parker (2004), 'Lost in translation?' Wall Street Journal (Eastern edn), 18 May, B1.

Lauring J. and H. Tange (2010), 'International language management: contained or dilute communication', European Journal of International Management, 4 (4), 317-32.

Louhiala-Salminen, L. and A. Kankaanranta (2012), 'Language issues in international internal communication: English or local language? If English, what English?' Public Relations Review, Special Edition on Internal Communication, 38 (2), 262-9.

Louhiala-Salminen, L., M. Charles and A. Kankaanranta (2005), 'English as lingua franca in Nordic corporate mergers: two case companies', English for Specific Purposes, 24 (4), 401-21.

Maclean, D. (2006), 'Beyond English: transnational corporations and the strategic management of language in a complex multilingual business environment', Management Decision, 44 (10), 1377-90.

Maitland, A. (1999), 'The case of the misleading coffin', Financial Times, 17 June.

Mann, F. (2004), 'From lingua franca to global English', Global Envision (www. globalenvision.org) created 28 July, 2004; accessed 9 August 2010.

Marschan, R., D.E. Welch and L.S. Welch (1996), 'Control in less-hierarchical MNC structures: the role of personal networks and informal communication', International Business Review, 5 (2), 137-50.

Marschan, R., D.E. Welch and L.S. Welch (1997), 'Language: the forgotten factor in multinational management', European Management Journal, 15 (5), $591-8$.

Marschan-Piekkari, R., D.E. Welch and L.S. Welch (1999), 'In the shadow: the impact of language on structure, power and communication in the multinational', International Business Review, 8 (4), 421-40.

McCrum, R., W. Cran and R. MacNeil (1986), The Story of English, London: Faber and Faber.

Michailova, S. and K. Husted (2003), 'Knowledge-sharing hostility in Russian firms', California Management Review, 45 (3), 59-77.

Nahapiet, J. and S. Ghoshal (1998), 'Social capital, intellectual capital, and the organizational advantage', Academy of Management Review, 23 (2), 242-66.

Nickerson, C. (2005), 'English as a lingua franca in international business contexts', English for Specific Purposes, 24 (4), 367-80.

O'Grady, S. and H.W. Lane (1996), 'The psychic distance paradox', Journal of International Business Studies, 27 (2), 309-33.

Planken, B. (2005), 'Managing rapport in lingua franca sales negotiations: a comparison of professional and aspiring negotiators', English for Specific Purposes, 24 (4), 381-400. 
Poncini, G. (2003), 'Multicultural business meetings and the role of languages other than English', Journal of Intercultural Studies, 34 (1), 17-32.

Reeves, N. and C. Wright (1996), Linguist Auditing, Clevedon, UK: Multinational Matters.

Seidlhofer, B. (2005), 'English as a lingua franca', ELT Journal, 59 (4), 339-41.

Sørensen, E.S. (2005), Our Corporate Language is English: An Exploratory Survey of 70 DK-sited Corporations' Use of English, Master's Thesis, Aarhus: Aarhus School of Business.

Tietze, S. (2004), 'Spreading the management gospel - in English', Language and Intercultural Communication, 4 (3), 175-89.

Tietze, S., L. Cohen and G. Musson (2003), Understanding Organisations through Language, London: Sage.

Tung, R.L. (1998), 'A contingency framework of selection and training of expatriates revisited', Human Resource Management Review, 8 (1), 23-37.

Welch, D.E. and L.S. Welch (2008), 'The importance of language in international knowledge transfer', Management International Review, 48 (3), 339-60.

Welch, D.E., L.S. Welch and R. Marschan-Piekkari (2001), 'The persistent impact of language on global operations', Prometheus, 19 (3), 193-209.

Welch, D.E., L.S. Welch and R. Piekkari (2005), 'Speaking in tongues: the importance of language in international management processes', International Studies of Management and Organization, 35 (1), 10-27.

White, D. (1997), 'Return of the conqueror', Financial Times, 3 March, 13.

Zucchella, A., G. Palamara and S. Denicolai (2007), 'The drivers of the early internationalization of the firm', Journal of World Business, 42 (3), 268-80. 